\title{
Las concesiones de indultos en España (2000-2008) ${ }^{1}$
}

\author{
Antonio Doval Pais ${ }^{2}$, Isidoro Blanco Cordero, Cristina Fernández-Pacheco \\ Estrada, Clara Viana Ballester *, Juan Carlos Sandoval Coronado \\ Universidad de Alicante \\ (*) Universitat de València
}

Manuscrito recibido el 25 de octubre de 2011 / Publicado el 11 de enero de 2012-01-10

\section{RESUMEN}

El objeto de este artículo es presentar los primeros resultados de la investigación realizada sobre las concesiones de indultos en España durante los años 2000-2008. Ante la falta de estadísticas de acceso público, se construyó una amplia base de datos que ha permitido conocer el número de indultos concedidos y su distribución conforme a distintas variables. La investigación ha posibilitado así obtener una importante información sobre la práctica del indulto y contrastar algunos datos oficiales, además de diversas hipótesis de trabajo sobre cada una de las variables analizadas (número de indultos concedidos, sexo de la persona beneficiaria, delito indultado, órgano sentenciador, pena afectada, extensión del indulto, condiciones aplicadas, gobierno y ministro firmante). El interés del trabajo reside tanto en los resultados obtenidos considerando la falta de otros estudios sobre el tema-, como en que permite conocer ciertos aspectos sobre las políticas públicas en materia de criminalidad.

Palabras clave: indulto, estadísticas, extinción responsabilidad criminal, política criminal

\footnotetext{
${ }^{1}$ Este trabajo se enmarca en el estudio sobre "El indulto como instrumento de justicia material (régimen jurídico-penal y penitenciario, alcance y perspectivas", que ha sido objeto de dos proyectos de investigación financiados, respectivamente, por la Universidad de Alicante (GRE08-P06) y la Conselleria d'Educació de la Generalitat Valenciana (GV/2009/095). Los autores agradecen a Andreea Preda, técnica de investigación a cargo del proyecto GRE08-P06, el esfuerzo realizado para la construcción de la base de datos estadística y sus magníficas aportaciones y al profesor Ángel León Valle sus valiosas orientaciones sobre los aspectos estadísticos del estudio.

2 Correspondencia con el autor: antonio.doval@ua.es
} 


\begin{abstract}
The aim of this paper is to present the first results of an empirical research on pardon granting in Spain from 2000 to 2008. Since there are no public statistics regarding pardons in Spain, a wide data base was set-up, enabling the analysis of aspects such as the number of pardons granted and its distribution in different variables. The research has revealed very significant patterns in the granting of pardons in Spain on the following aspects: number of pardons, sex of the person, crime committed, tribunal competent for the crime, extent of the pardon, complementary conditions imposed, government and Minister granting the pardon. The results are very unique due to the lack of such studies and the fact that they also highlight certain aspects of public criminal policy.
\end{abstract}

Key words: pardon, statistics, extinction of criminal responsibility, criminal policy

\title{
1. INTRODUCCIÓN
}

El indulto es una institución jurídica extraordinaria. A pesar de que los ordenamientos jurídicos de los Estados democráticos la contemplan, constituye una excepción al normal funcionamiento de la Administración de Justicia, ya que en su virtud el poder ejecutivo puede declarar extinguida o modificada la pena impuesta por un juez o tribunal en una sentencia firme. La razón a la que, en principio, responde es que la aplicación del Derecho penal resulta en ocasiones excesivamente rigurosa o es por otros motivos insatisfactoria.

En el caso de España, el indulto se contempla en la Constitución como una prerrogativa del Rey que se ha de ejercitar "con arreglo a la ley" (art. 62, i C.E.) ${ }^{3}$. La ley que lo regula específicamente es la vieja — aunque modificada ${ }^{4}$ — Ley "provisional" de 18 de junio de 1870, por la que se establecen normas para el ejercicio de la Gracia de Indulto. Pero también está contemplado en el Código penal, donde figura entre las causas que extinguen la responsabilidad penal (art. 130.1.4 $4^{\circ}$ y como un remedio para cuando "de la rigurosa aplicación de las disposiciones de la Ley resulte penada una acción u omisión que, a juicio del Juez o Tribunal, no debiera serlo, o cuando la pena

\footnotetext{
${ }^{3}$ Pese a su denominación como "prerrogativa" en los arts. $87.3^{\circ}$ y $102.3^{\circ}$ C.E., no es propiamente tal ya que carece de la libertad del acto ejecutado por el Monarca, en el sentido de no necesidad del refrendo ministerial (vid. Rodríguez Zapata, 1987, 86-87; Aguado Renedo, 2001, 125-129).

${ }^{4}$ Su última -pero no única-reforma se debió a la Ley 1/1988, de 14 de enero, por la que se modifica la Ley de 18 de junio de 1870, estableciendo reglas para el ejercicio de la Gracia de Indulto.
} 
sea notablemente excesiva, atendidos el mal causado por la infracción y las circunstancias personales del reo" (art. 4.3).

Los indultos se conceden individualmente por medio de reales decretos que se publican en el Boletín Oficial del Estado (B.O.E.). Pero no existen datos oficiales accesibles al público ${ }^{5}$ que, de una forma agregada, permitan conocer periódicamente el número y el alcance de los concedidos y otras importantes circunstancias (como, por ejemplo, la clase de delitos indultados, la extensión de las penas remitidas o las condiciones impuestas a los beneficiarios de la gracia), ni tampoco es posible saber a qué criterios se atiende para obtener la gracia. La única información sobre estos aspectos la ofrecen las ocasionales declaraciones de los ministros de justicia en sus comparecencias en las Cortes; pero, además de irregulares, son muy escasas ${ }^{6}$.

Esto dificulta la comprobación del uso que se hace del indulto en la práctica e impide, por consiguiente, su valoración, así como la posibilidad de corregir los eventuales problemas que el recurso al mismo ponga de manifiesto (por ejemplo, a raíz de su concentración en torno a unos determinados delitos), obstaculizándose, en consecuencia, la posibilidad de realizar las oportunas correcciones legislativas.

Por todo ello, a partir de la información disponible en los reales decretos sobre concesiones de indulto, se ha elaborado una base de datos con el fin de conocer la realidad de la aplicación de este instituto.

Frente a la bibliografía existente sobre el régimen jurídico del indulto en España, que reúne importantes trabajos de carácter teórico, el presente estudio ofrece un análisis de naturaleza empírica cuya singularidad reside no sólo en su enfoque, sino sobre todo en el diseño y la construcción de una base de datos exhaustiva sobre las personas indultadas durante el amplio periodo escogido.

A continuación se describirán los aspectos metodológicos del estudio y los resultados alcanzados. El trabajo terminará con unas conclusiones y la formulación de una propuesta para superar las limitaciones metodológicas que afectan a la información disponible.

\footnotetext{
${ }^{5}$ Poniéndolo también de manifiesto, Cid y Tébar (2010).

${ }^{6}$ Por ejemplo, la comparecencia de D. Ángel Acebes con ocasión de los 1443 indultos concedidos en diciembre de 2000 en la sesión de 13-12-2000 de la Comisión de Justicia e Interior (Diario de Sesiones. Congreso de los Diputados, Comisiones. Justicia e Interior, VII Legislatura, núm. 121, p. 3500) o la de D. Juan Fernando López Aguilar ante la Comisión de Justicia del Congreso en la sesión de 25-5-2004 (DSC, Comisiones, Justicia, VIII Legislatura, núm. 33, 2004. Sesión n ${ }^{\circ} 2$ de la Comisión de Justicia, pp. 1 y ss.).
} 


\section{MÉTODO}

\subsection{Fuentes}

La información sobre la concesión de indultos en España puede encontrarse en dos fuentes oficiales: la fuente primaria está constituida por los reales decretos de concesión de los indultos; la secundaria, por las declaraciones de los ministros de justicia en sus comparecencias en las Cortes Generales. El presente estudio ha tenido en cuenta ambas fuentes; sin embargo, dado que la naturaleza y la finalidad de la información suministrada por la segunda han incidido directamente en el número, la regularidad y la calidad de los datos, y resulta insuficiente, ha sido imprescindible acudir a la fuente descrita como primaria.

Los registros utilizados para construir la base de datos de este trabajo no constituyen una muestra, sino que integran el universo poblacional de la totalidad de los indultos concedidos entre los años 2000 y 2008 en España por delitos previstos en la ley penal común (no militar).

La delimitación del periodo sometido al análisis obedece al interés por conocer si la distinta orientación política de los gobiernos afecta al régimen de los indultos. Precisamente, el intervalo escogido permite verificar este extremo al abarcar el curso sucesivo más reciente de dos legislaturas de distinto signo político (VII Legislatura, 2000-2004, Gobierno del Partido Popular; VIII Legislatura, 2004-2008, Gobierno del Partido Socialista Obrero Español).

La información se ha extraído de los reales decretos de concesión de los indultos, publicados en el B.O.E., a partir de la cual ha sido sistematizada la base de datos. Estas disposiciones contienen unas referencias de carácter personal (nombre y sexo), junto a otras de naturaleza procesal (órgano jurisdiccional del que procede la sentencia firme, informes atendidos) y otras de carácter penal-sustantivo (título de imputación, delito o falta cometido, pena impuesta), y concluyen con la determinación del alcance o efecto del indulto, la condición temporal eventualmente impuesta y las correspondientes firmas del Rey y el Ministro de Justicia. A partir de la información que proporcionan los decretos de indulto, se han construido diversas variables, desglosadas en las siguientes categorías: 


\begin{tabular}{|c|c|c|c|c|c|c|c|}
\hline $\begin{array}{c}\text { Contexto } \\
\text { político }\end{array}$ & $\begin{array}{c}\text { Características } \\
\text { individuales }\end{array}$ & Tiempo & Espacio & $\begin{array}{c}\text { Calificación } \\
\text { jurídica }\end{array}$ & Penas & \begin{tabular}{|c} 
Características \\
del indulto
\end{tabular} & $\begin{array}{c}\text { Condiciones } \\
\text { impuestas }\end{array}$ \\
\hline $\begin{array}{l}\text { - Año R.D. } \\
\text { de } \\
\text { concesión } \\
\text { del indulto } \\
\text { - Ministro } \\
\text { firmante }\end{array}$ & \begin{tabular}{|l} 
- Sexo de la \\
persona \\
indultada
\end{tabular} & $\begin{array}{l}\text { - Año de los } \\
\text { hechos } \\
\text { - Fecha de } \\
\text { la sentencia } \\
\text { - Fecha } \\
\text { R.D. de } \\
\text { concesión } \\
\text { del indulto } \\
\text { - Fecha } \\
\text { BOE }\end{array}$ & \begin{tabular}{|l|} 
- Órgano \\
sentenciador \\
\\
- Provincia \\
del órgano \\
sentenciador
\end{tabular} & \begin{tabular}{|l} 
- Título de \\
responsabilidad \\
(autoría o \\
participación) \\
\\
- Delitos \\
cometidos \\
\\
- Grado de \\
ejecución (acto \\
preparatorio, \\
tentativa o \\
consumación)
\end{tabular} & $\begin{array}{l}\text { - Penas } \\
\text { principales } \\
\text { y duración } \\
\text { - Penas } \\
\text { accesorias y } \\
\text { duración } \\
\text { - Pena } \\
\text { afectada por } \\
\text { el indulto }\end{array}$ & $\begin{array}{l}\text { - Clase de indulto } \\
\text { (total o parcial, } \\
\text { con conmutación } \\
\text { o no) } \\
\text { - Extensión del } \\
\text { indulto parcial y } \\
\text { pena resultante }\end{array}$ & \begin{tabular}{|l} 
- Plazo de no \\
comisión de \\
delitos dolosos \\
- Sumisión a \\
tratamiento \\
deshabituador \\
- Satisfacción de \\
la \\
responsabilidad \\
civil \\
- Otras
\end{tabular} \\
\hline
\end{tabular}

\subsection{Objetivo e hipótesis}

Con este trabajo se pretende conocer las características que presenta el régimen de concesión de los indultos en España. Con este fin, se han planteado las siguientes hipótesis:

$1^{\text {a }}$. El distinto signo político del Gobierno determina un mayor o menor recurso al indulto, según se trate, respectivamente, de un gobierno progresista o de uno conservador.

$2^{\mathrm{a}}$. Las características y circunstancias personales del condenado inciden en la concesión del indulto. En particular, se concederían más indultos a mujeres que a hombres.

3a. El número de indultos concedidos muestra ordinariamente una escasa variación anual.

$4^{\mathrm{a}}$. Los indultos se distribuyen geográficamente de un modo uniforme en términos relativos.

$5^{\mathrm{a}}$. Existen clases de delitos que no se indultan.

$6^{\mathrm{a}}$. Algunas clases de delitos se indultan más que otras.

$7^{\text {a }}$. La mayoría de los indultos afectan a penas privativas de libertad.

$8^{\text {a }}$. La mayoría de los indultos son parciales, y no totales.

9a . La mayoría de los indultos concedidos son condicionados. 
Seguidamente, se revisará cada una de las mismas a la luz de los datos aportados por el análisis de las diferentes variables.

\section{RESULTADOS}

\subsection{Contexto político}

En la medida en que el órgano que concede el indulto es el poder ejecutivo, puede afirmarse que esta institución tiene un claro carácter político. Ello, unido a la falta de transparencia del proceso y a la ausencia de una regulación pormenorizada de las circunstancias que motivan la concesión o denegación del indulto, hace especialmente oportuno tener en cuenta las variables referidas al contexto político en el que el indulto tuvo lugar y, en particular, el ministro que lo concedió.

Teniendo en cuenta estos aspectos —y como ya se indicó-, el universo ha sido seleccionado para abarcar un amplio período que comprenda el gobierno de dos distintos partidos con el fin de poder revisar la posible influencia de la diferente ideología política en el régimen de los indultos.

El primer aspecto relevante que se extrae del contexto político se refiere al porcentaje de indultos concedidos por cada Gobierno con respecto al total. Los resultados se muestran en el siguiente gráfico.

\section{Gráfico 1: Distribución por Gobiernos}

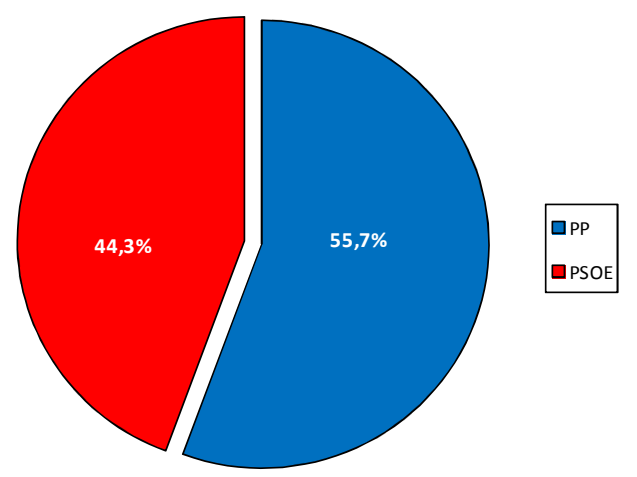

Fuente: elaboración propia. 
A partir de los datos recabados se ha podido constatar que el Gobierno del PP concedió entre 2000 y 2004 un número notablemente mayor de indultos que el Gobierno del PSOE. Como puede observarse a partir de los valores porcentuales mostrados, la diferencia en términos absolutos es de 11,4\%.

No obstante, interesa comparar los datos anteriores con los referidos al número total de penados en el mismo período con el fin de poder observar si en términos relativos las cifras de los indultos de uno y otro Gobierno fueron, sin embargo, semejantes. Hay que advertir que se trata de una comparación puramente orientativa, puesto que los indultos concedidos entre 2000 y 2008 no necesariamente corresponden a delitos cometidos en este mismo intervalo de tiempo.

Las tasas resultantes confirman que, considerado el número de penados, durante el gobierno del PSOE, efectivamente, fueron indultadas menos personas $(2,8 \%$ ) que a lo largo del gobierno del PP $(5,8 \%)^{7}$. Ello no permite, pues, corroborar la hipótesis según la cual un gobierno de ideología progresista — teniendo en cuenta su clásico ideario político-criminal (Borja, 2011)_ sería más indulgente que un gobierno conservador.

Un segundo aspecto que se ha considerado de interés es la observación de los datos atendiendo al ministro firmante de los decretos. En términos absolutos, D. Ángel Acebes figura con mayor frecuencia (40,6\%), seguido por D. Juan Fernando López Aguilar (27\%), D. Mariano Fernández Bermejo (17,4\%), D. José María Michavila $(10,3 \%)$ y, por último, Dña. Margarita Mariscal de Gante (4,71\%).

Aunque tales cifras son ya expresivas, si se tiene en cuenta que la duración de los mandatos de los ministros fue distinta, es particularmente interesante conocer la tasa media diaria de indultos que corresponde a cada uno de ellos. Los resultados pueden observarse en el siguiente gráfico.

\footnotetext{
${ }^{7}$ El total de los penados del periodo según el INE (Estadística de condenados) es de 1.191.417, de los que 451.870 corresponderían al periodo de gobierno del PP y 739.546 al del PSOE. Considerando que la VIII Legislatura comenzó a principios de abril de 2004 y que el día 19 del mismo mes se celebró el primer Consejo de Ministros, se ha atribuido al Gobierno saliente los penados de los tres primeros meses de 2004 (11.171 al mes x 3 meses = 33513) y al del PSOE los restantes. La enorme desproporción que se observa entre ambas cifras podría deberse a los efectos del punitivismo que caracterizó a las reformas penales de 2003 (LL. OO. 7, 11 y 15/2003).
} 
Gráfico 2: Tasa de indultos por ministro y día

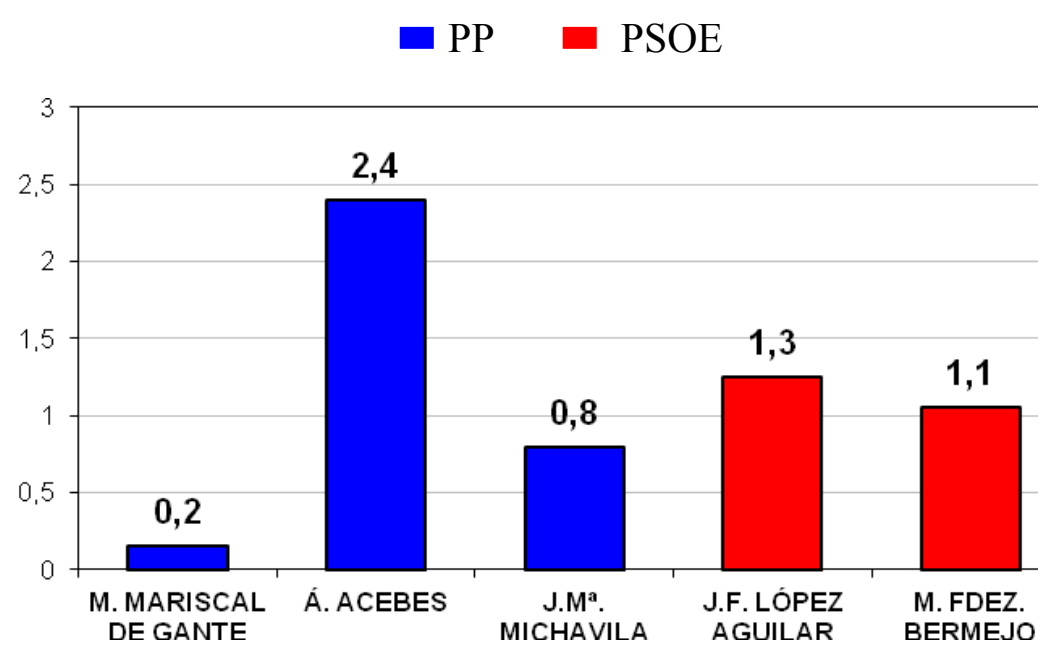

Fuente: elaboración propia.

A la vista de estos datos, es posible confirmar que también desde esta óptica el ministro con una mayor tasa de indultos bajo su mandato es D. Ángel Acebes. Además, la diferencia es muy notable en comparación con las cifras correspondientes a los restantes ministros de ambos Gobiernos.

Tanto a efectos de la interpretación de los datos por partido en el gobierno, como por ministros de justicia, es necesario tener en cuenta que en diciembre de 2000 , precisamente siendo el titular D. Ángel Acebes, fueron concedidos 1333 indultos en un solo día. Desde luego, esta cifra posee un carácter claramente excepcional —en este caso, amparado en diversos acontecimientos, como el cambio de milenio o la celebración del año jubilar, entre otras razones ${ }^{8}$ - , pero se trata de indultos efectivos cuya consideración en este estudio resulta imprescindible.

En suma, se observa que el Gobierno del PP concedió más indultos que el del PSOE, aunque las cifras relativas colocaron al Gobierno socialista en una posición notablemente peor a causa, probablemente, de los efectos de las reformas de $2003^{9}$.

\footnotetext{
${ }^{8}$ Comparecencia del Ministro de Justicia de 1-12-2000 (DSC, cit., pp. 3500 y ss.).

${ }^{9}$ No es descartable que además hubiera muchas peticiones sin resolver. En 2005, el Ministro López Aguilar informó de la necesidad de descongestionar la situación y, de hecho, la progresión de indultos concedidos es visible, infra, en el gráfico 3.
} 


\subsection{Características individuales de la persona indultada}

Otra de las hipótesis de partida de este trabajo es que las características y circunstancias particulares de la persona penada influirían en la concesión del indulto, considerando su relación con ciertos factores estimados relevantes al efecto (como, entre otros, las responsabilidades familiares ${ }^{10}$ ).

Ahora bien, al plantear el estudio de este grupo de variables se halló un obstáculo insalvable, ya que ni los decretos incluyen información alguna sobre dichas circunstancias, ni existen otras fuentes oficiales de las que se puedan obtener tales datos $^{11}$. En consecuencia, el único aspecto relativo a las características particulares de la persona indultada que ha podido ser medido es el sexo, deducible del tratamiento antepuesto a los nombres (don, doña) que aparece en los reales decretos.

El dato tiene interés para contrastar la hipótesis de que, proporcionalmente, se concederían más indultos a mujeres que a hombres, fundamentada en la relación de esta variable con los factores relevantes que se ha señalado que pueden influir para ello.

Pues bien, aunque las cifras absolutas permiten observar que son más los hombres indultados $(85,8 \%)$, si se considera el número de personas penadas en ese periodo $^{12}$, se confirma la hipótesis, puesto que resulta que las mujeres son indultadas con mayor frecuencia que los hombres. Dado que el número de varones penados es sustancialmente superior al de mujeres, disminuye el peso relativo de los indultos de aquéllos, como se refleja en la siguiente tabla.

Tabla 1: Tasa de indultados sobre penados*

\begin{tabular}{|c|c|c|c|}
\hline & $\begin{array}{c}\text { VARONES } \\
(\%)\end{array}$ & $\begin{array}{c}\text { MUJERES } \\
(\%)\end{array}$ & TOTAL \\
\hline $\begin{array}{c}\text { PENADOS EN EL PERIODO } \\
\text { ANALIZADO }\end{array}$ & 92,19 & 7,81 & 1.191 .417 \\
\hline $\begin{array}{c}\text { INDULTADOS EN EL PERIODO } \\
\text { ANALIZADO }\end{array}$ & 85,79 & 14,21 & 4.667 \\
\hline $\begin{array}{c}\text { PORCENTAJE INDULTOS SOBRE } \\
\text { TOTAL PENADOS }\end{array}$ & 0,37 & 0,72 & $0,39 \%$ \\
\hline
\end{tabular}

* En la Estadística de condenados del INE sorprende que no conste el sexo de un total de 80676 personas penadas (el 6,8\% del total del

\footnotetext{
${ }^{10}$ Comparecencia del Ministro de Justicia de 1-12-2000, cit., p. 3502.

${ }^{11}$ Aparte de alguna referencia aislada a circunstancias como la avanzada edad del penado o la existencia de enfermedades incurables (BOCG, Congreso, serie D, 21-4-2005, p. 250.).

${ }^{12}$ De nuevo, debe tenerse en cuenta el desfase que conlleva el cálculo, puesto que, como ya se indicó, los indultos concedidos en un determinado período no se corresponden con los penados en el mismo lapso.
} 
periodo), que se ha atribuido en esta tabla conforme a la distribución observada.

Fuente: INE (Estadística de condenados) y elaboración propia.

Como se aprecia en la tabla anterior, mientras el 0,37\% de los delitos cometidos por hombres son indultados, en el caso de las mujeres lo son el 0,72\%. A pesar de que se trata de porcentajes muy bajos, la diferencia entre ambas cifras es sustancial. En consecuencia, resulta que —en términos relativos- las mujeres han sido más beneficiadas por los indultos. Los posibles motivos para ello podrían deberse a la diferente relación de las categorías de esta variable (hombre o mujer) con factores tales como la menor peligrosidad (basada en la observación de las cifras de delincuencia femenina), o las responsabilidades familiares.

\subsection{Tiempo}

La referencia temporal de los indultos concedidos es fundamental para este estudio y ha constituido por ello uno de los principales objetivos de la investigación. Como ya se indicó, oficialmente no se proporcionan cifras acumuladas que permitan conocer el número total de indultos de un periodo. Pero los datos de naturaleza temporal que aportan los reales decretos no se limitan a esta información.

El grupo de variables temporales recoge, específicamente: el año de comisión de los hechos, la fecha de la sentencia condenatoria firme, la fecha del real decreto de concesión del indulto y la fecha de publicación del mismo en el B.O.E.

Con la medición de esta variable se pretende confirmar la hipótesis según la cual el número de indultos no varía sustancialmente de un año a otro. Sin embargo, como se observa en el siguiente gráfico, ello no ha sido así durante el periodo analizado. 


\section{Gráfico 3: Número de indultos concedidos por año (2000-2008)}

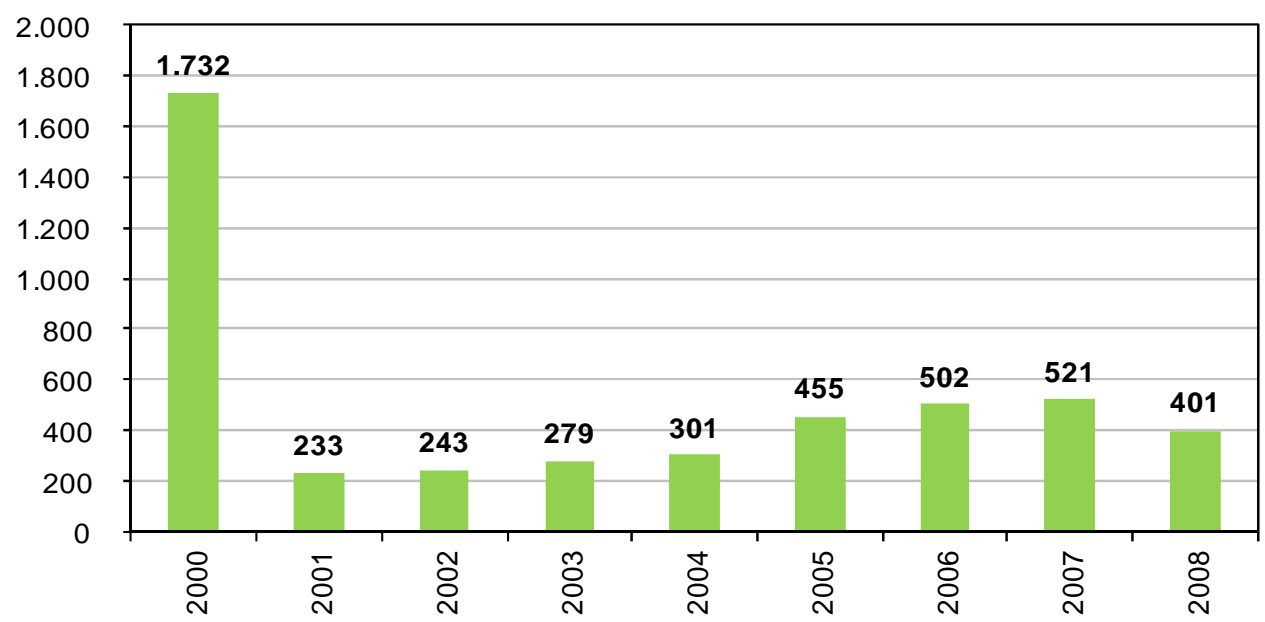

Fuente: elaboración propia.

Efectivamente, en 2000 se produjo una importante desviación con respecto a la tendencia que puede observarse en adelante, caracterizada por un suave crecimiento desde 2001 hasta 2007 (algo más moderado desde 2004). No obstante, los datos referidos al último año del estudio muestran que el número de indultos descendió.

De los datos obtenidos resulta que la media mensual de los concedidos durante el periodo (2000-2008) fue de 519 ( $\approx 43 / \mathrm{mes})$. No es posible, sin embargo, determinar su proporción en relación con los solicitados por la falta de datos sobre estos últimos ${ }^{13}$.

Con el fin de valorar el significado de esta cifra, se ha considerado el número de personas penadas durante el mismo periodo. No obstante, esta comparación —como ya se ha advertido_ no puede más que ofrecer una mera estimación aproximada, en la medida en que un número significativo de las personas beneficiarias del indulto en el periodo no se corresponden con las penadas en el mismo intervalo.

Durante el periodo analizado el número de penados fue de 1.191.417. Siendo el número total de personas indultadas 4667 , resulta una tasa de indultados de $3,9 \%$, lo que significa que de cada 1000 personas penadas, prácticamente 4 habrían sido indultadas.

${ }^{13}$ Únicamente, se hallan algunas referencias en las comparecencias de los ministros de justicia. Vid., por ejemplo, la del Sr. Acebes para informar sobre el acuerdo de concesión de indultos adoptado por el Consejo de Ministros el 1-12-2000 (DSC, cit., ibid.) y la del Sr. López Aguilar en la Sesión del Pleno del Senado de 22-3-2006 (DSS, VIII Legislatura, núm. 75, p. 4323). 


\subsection{Espacio}

El grupo de variables relativas al espacio viene determinado por el órgano jurisdiccional que condenó (o confirmó la condena) por la comisión de, al menos, una infracción penal al sujeto indultado. Para la presente investigación se han extraído de los reales decretos tanto los datos relativos a los órganos que juzgaron los hechos, como a la provincia en la que tales órganos tienen su sede.

La variable referida a los órganos jurisdiccionales es expresiva desde el punto de vista de lo que puede significar el agotamiento de las instancias de recurso por el interesado. Por ello se ha recopilado el dato referido a la posición jerárquica del mismo. El análisis realizado ha permitido obtener los siguientes resultados:

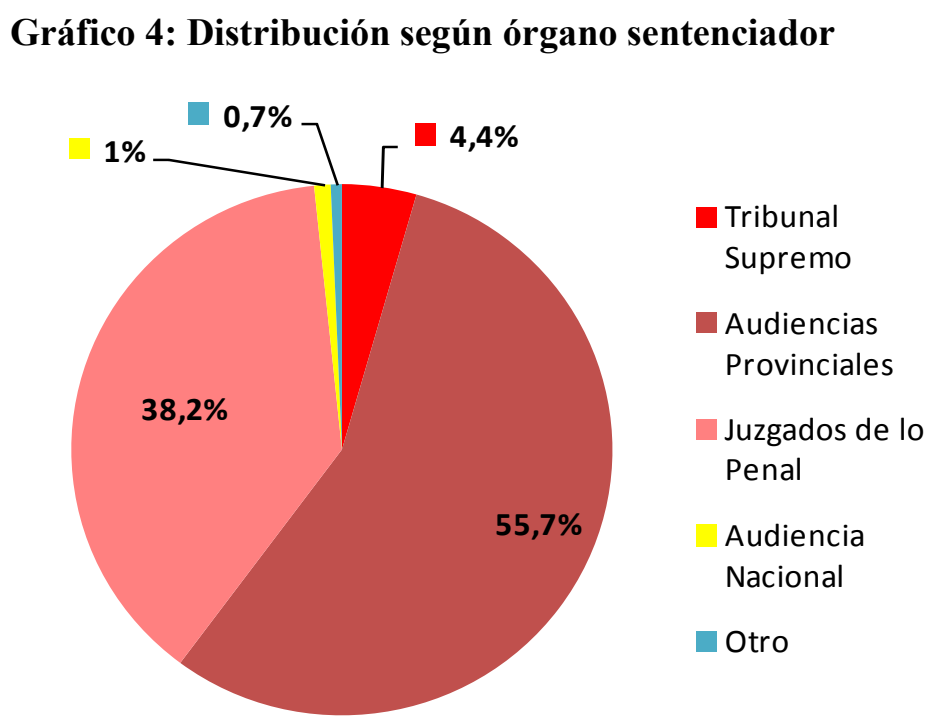

Fuente: elaboración propia.

Como se observa en el gráfico, más de la mitad de los indultos concedidos entre 2000 y 2008 recayeron sobre resoluciones de las audiencias provinciales, a los que siguieron los que beneficiaron a condenados por juzgados de lo penal. Ello parece lógico, puesto que estas instancias son las que acumulan mayores competencias en la materia.

El análisis de estos datos también podría ofrecer alguna información de interés a efectos de determinar qué instancias solicitan indultos con mayor frecuencia, desde la lógica de que una parte de los indultos concedidos tiene su origen en una solicitud de las 
propias instancias judiciales. No obstante, de nuevo se opone el obstáculo de la escasez de datos oficiales, en la medida en que no existen registros públicos que determinen el origen de la petición del indulto, ni tampoco consta en los decretos ${ }^{14}$.

También resulta interesante examinar la información obtenida en lo que respecta a la provincia donde fueron dictadas las sentencias condenatorias cuyas penas fueron objeto del indulto. Los datos correspondientes a esta variable se muestran en el siguiente gráfico:

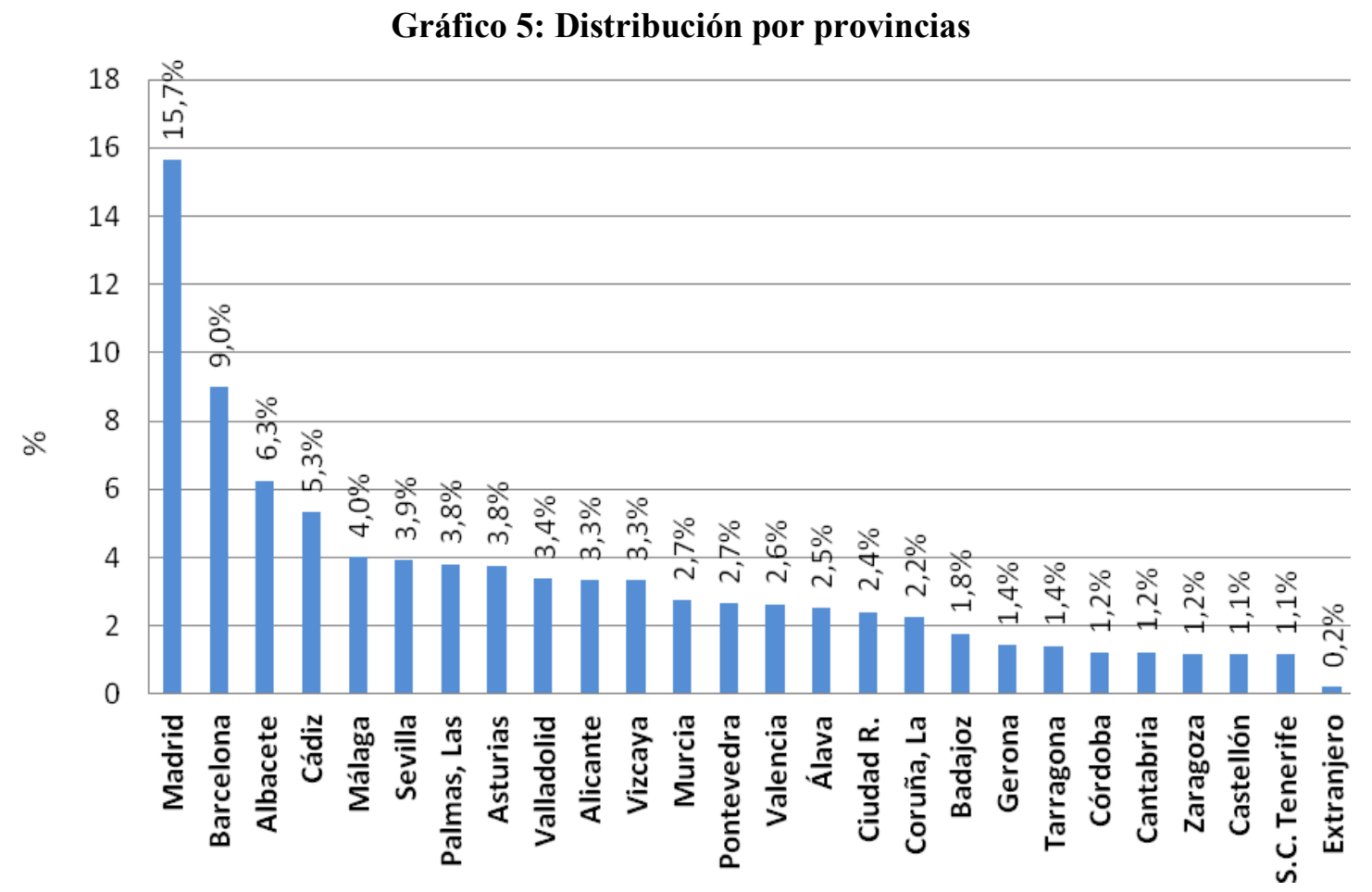

Nota: Se recogen únicamente los valores a partir del 1\%, con excepción del caso de las sentencias dictadas por órganos jurisdiccionales extranjeros, que se ha considerado un dato de interés.

Fuente: elaboración propia.

Como se ve, el mayor número de indultos recae en condenados por órganos jurisdiccionales radicados en Madrid (15,7\%) y, después, en Barcelona (9\%). La gran diferencia que se aprecia entre las cifras de Madrid y las demás capitales no se explica solamente a partir de la incidencia de las sentencias dictadas por la Audiencia Nacional y por el Tribunal Supremo, pues en total apenas superan conjuntamente un 5\%.

\footnotetext{
${ }^{14}$ Ahora bien, puesto que solamente podrán ser indultados los condenados por sentencia firme (art. $2.1 \mathrm{de}$ la Ley del indulto), cabe suponer que la mayor frecuencia de sentencias firmes de audiencias provinciales y juzgados de lo penal — sin ulterior recurso_ — pone de manifiesto el origen judicial de la solicitud del indulto, al menos, en bastantes casos.
} 
En todo caso, para valorar adecuadamente los datos resulta imprescindible comparar las cifras obtenidas con los índices de penados por provincia. Sin embargo, se alza para ello el obstáculo de la falta de los correspondientes datos de penados desagregados por provincias en la base de datos del INE. Con el fin de suplir de algún modo esta carencia, se ha procedido a la comparación de los datos de los beneficiados por los indultos con los de los penados en las comunidades autónomas uniprovinciales para conseguir las tasas que se recogen en la siguiente tabla:

Tabla 2: Tasa de indultados en Comunidades Autónomas uniprovinciales

\begin{tabular}{|l|c|c|c|}
\hline & $\begin{array}{c}\text { TOTAL } \\
\text { PENADOS }\end{array}$ & $\begin{array}{c}\text { TOTAL } \\
\text { INDULTOS } \\
\text { CONCEDIDOS }\end{array}$ & $\begin{array}{c}\text { PORCENTAJE } \\
\text { SOBRE PENADOS } \\
\text { EN EL MISMO } \\
\text { PERIODO }\end{array}$ \\
\hline Madrid & 156.684 & 736 & $0,47 \%$ \\
\hline Murcia & 52.566 & 129 & $0,25 \%$ \\
\hline Illes Balears & 43.804 & 34 & $0,08 \%$ \\
\hline Asturias & 35.202 & 177 & $0,50 \%$ \\
\hline Cantabria & 18.341 & 58 & $0,32 \%$ \\
\hline Navarra & 17.761 & 42 & $0,24 \%$ \\
\hline Ceuta & 12.448 & 3 & $0,02 \%$ \\
\hline La Rioja & 11.023 & 35 & $0,32 \%$ \\
\hline Melilla & 7.249 & 5 & $0,07 \%$ \\
\hline
\end{tabular}

Fuente: elaboración propia.

Las tasas obtenidas ponen de manifiesto que, en términos relativos, la Comunidad de Madrid cede el primer puesto en el número de indultos al Principado de Asturias. Con todo, a fin de llevar a cabo un análisis integral de esta variable, sería imprescindible contar con los mencionados datos desagregados, de cuyo examen se podrían extraer consecuencias claras a estos efectos.

\subsection{Calificación jurídica}

Bajo la referencia a la calificación jurídica se ha examinado un grupo de variables que es fundamental en el presente estudio y que alude al delito cometido, así como al título de responsabilidad y al grado de ejecución.

En primer lugar, la medición de la variable relativa al delito cometido permite determinar si el delito por el cual el sujeto ha sido condenado influye en la concesión 
del indulto. De esta manera, se podrá comprobar si algunos delitos se benefician del indulto con mayor frecuencia; si se indulta toda clase de delitos, solo algunos (graves, menos graves) o también las faltas; si se conceden indultos a condenados por concursos de delitos o si solo se otorgan en los supuestos de condena por un único delito; o si se indultan delitos que, de acuerdo con las declaraciones del Gobierno, no se deberían indultar.

Al respecto, las hipótesis que se pretenden confirmar son las siguientes. En primer lugar, que el indulto no se concede respecto de todas las clases de delito (quedando excluidos a priori muchos de ellos, como los delitos sexuales, los delitos relativos a la violencia de género, los delitos relacionados con el crimen organizado, los delitos de terrorismo o los delitos de torturas o relacionados con la corrupción). En segundo lugar, que existen delitos que se indultan más frecuentemente que otros de igual o menor gravedad.

La primera de las hipótesis se ha basado en las declaraciones de los representantes de los Gobiernos de turno durante el periodo analizado. De acuerdo con las mismas, estarían excluidos de la concesión de indulto los delitos que "plantean un particular rechazo social", como son los siguientes: delitos de terrorismo o de quienes tienen antecedentes terroristas, crimen organizado, malos tratos, agresión o tráfico sexual, violencia doméstica, torturas, tráfico de drogas graves, casos en los que fue apreciada y estaba acreditada una reiteración significativa ${ }^{15}$, delitos relacionados con la seguridad vial y delitos de corrupción o enriquecimiento ilícito en el ejercicio de cargos públicos $^{16}$.

Sin embargo, sí han sido indultados delitos expresamente excluidos por los Gobiernos, como se observa en la siguiente tabla ${ }^{17}$.

\footnotetext{
${ }^{15}$ Comparecencia del Ministro de Justicia para informar sobre el acuerdo de concesión de indultos adoptado por el Consejo de Ministros el 1-12-2000 (DSC, cit., p. 3502).

${ }^{16}$ Vid. López Aguilar en el prólogo a García Mahamut (2004). También, en su comparecencia ante la Comisión de Justicia del Congreso (DSC, Comisiones, Justicia, $n^{o} 33,2004$. Sesión $n^{\circ} 2$ de la Comisión de Justicia, p. 39).

${ }^{17}$ No es posible contar con información exacta sobre la clase de delitos indultados. Por ejemplo, se afirma que se excluyen los "delitos de agresión sexual" (ataques con violencia o intimidación). Sin embargo, los datos muestran que se han indultado "delitos sexuales" que no es posible saber si son de esta clase. Igual sucede en otros casos.
} 
Tabla 3: Delitos indultados (selección)

\begin{tabular}{|c|c|c|}
\hline DELITO & Número & $\begin{array}{c}\% \text { sobre total } \\
\text { delitos }\end{array}$ \\
\hline Delitos contra la seguridad del tráfico & 345 & $5,59 \%$ \\
\hline Delitos de malversación y fraude & 94 & $1,52 \%$ \\
\hline $\begin{array}{c}\text { Delito de terrorismo, tenencia de armas, } \\
\text { explosivos y colaboración con banda } \\
\text { armada }\end{array}$ & 51 & $0,83 \%$ \\
\hline Delitos de cohecho & 15 & $0,24 \%$ \\
\hline Delitos sexuales & 3 & $0,05 \%$ \\
\hline Delitos de violencia doméstica & 1 & $0,02 \%$ \\
\hline
\end{tabular}

Fuente: elaboración propia.

Realmente, los datos permiten comprobar que hay pocos delitos que no sean objeto de indulto, y que las prácticas de concesión de indulto contradicen lo declarado por los ministros. Por lo demás, se ha constatado que durante el periodo no ha habido indultos, entre otros, por delitos de lesiones al feto, delitos relativos a la manipulación genética, delitos de rebelión y delitos contra la Corona, delitos de sedición, delitos de traición y contra la paz o la independencia del Estado y relativos a la Defensa Nacional.

Sí se verifica la hipótesis de que existen delitos que se indultan más frecuentemente que otros de igual o menor gravedad. Un ejemplo es el relativo a los delitos contra la salud pública, que en algunos casos pueden llevar aparejadas penas de enorme gravedad, y pese a ello se indultan con más frecuencia que otros con menores penas como los delitos contra el patrimonio. 


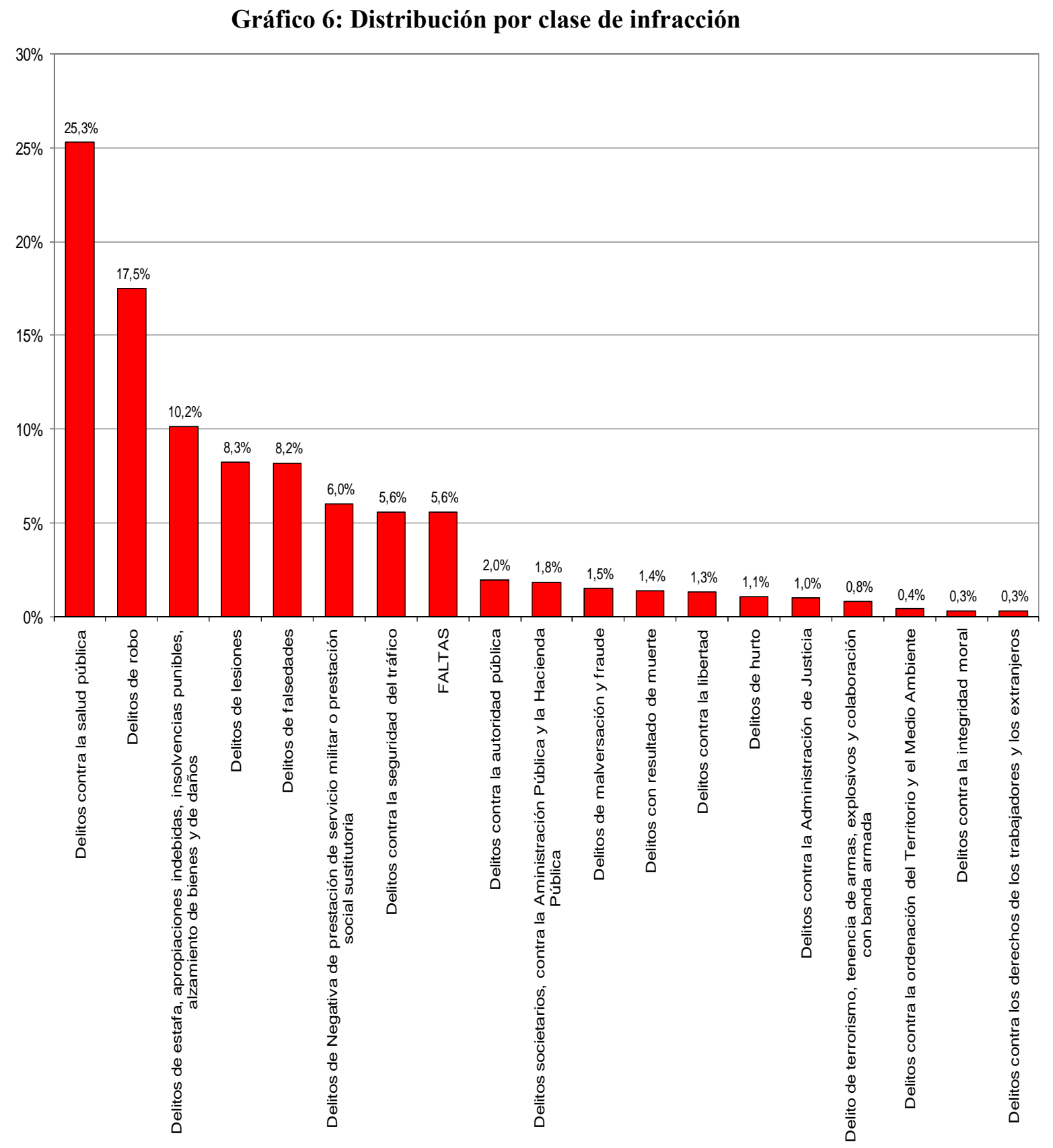

Fuente: elaboración propia

No obstante, las frecuencias observadas sobre los delitos más indultados pueden expresar más. Si se compara el total de los penados en el mismo periodo con el número de indultados por la misma clase de delitos, es posible obtener las siguientes tasas: 
Gráfico 7: Tasa de indulto por clase de delito

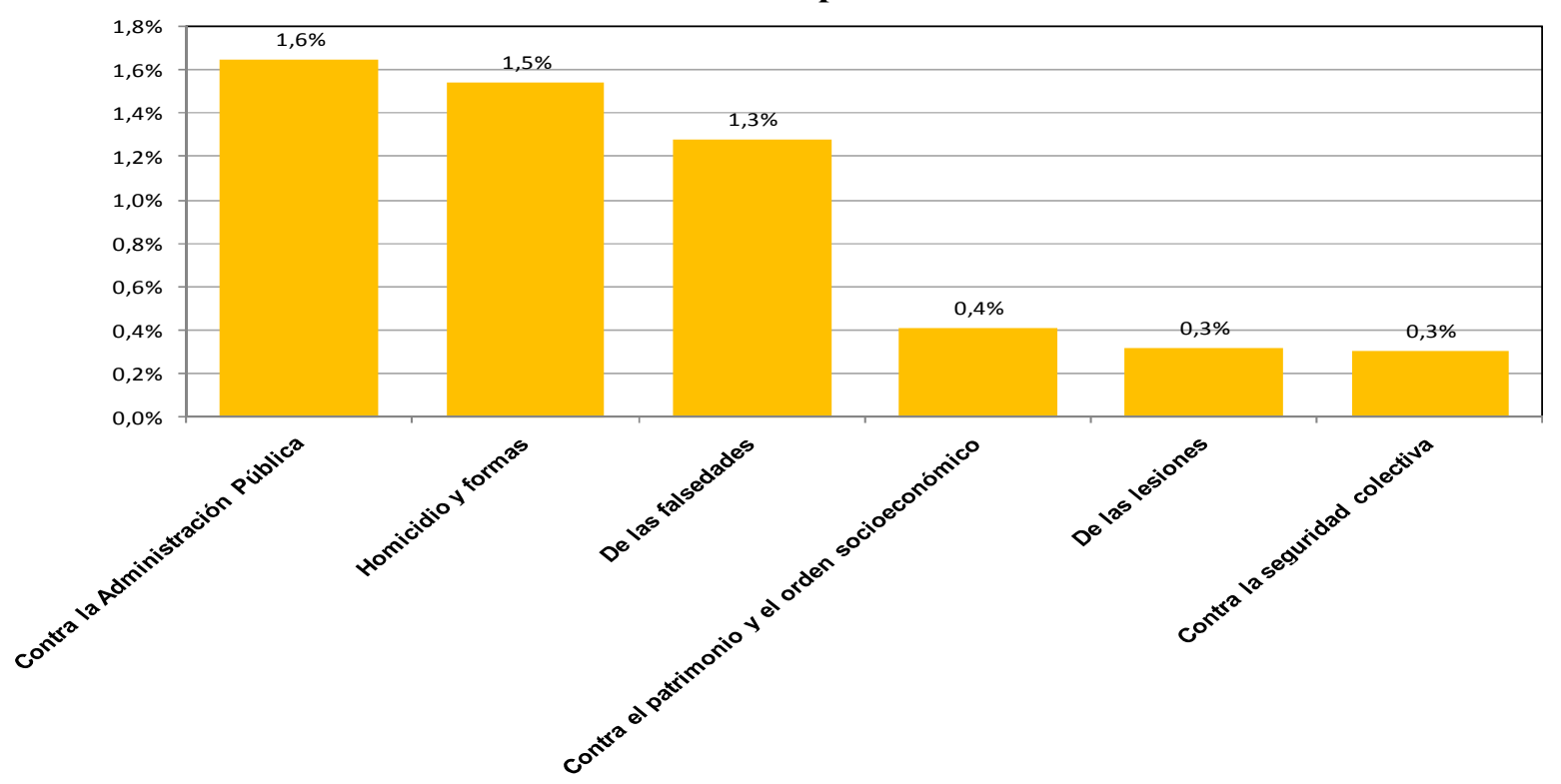

Fuente: Estadísticas de condenados (INE) y elaboración propia.

El diagrama anterior recoge la proporción de personas indultadas según la clase de delito, es decir, la tasa de indultos en comparación con el número de personas penadas por determinadas clases de delito (las más representativas) ${ }^{18}$. El resultado es interesante porque permite constatar que los delitos más indultados —en estos términos proporcionales - son los delitos contra la Administración pública, seguidos muy de cerca por los de homicidio y sus formas, y no los delitos contra la salud pública — como cabría esperar, a la vista de los datos absolutos (gráfico 6)—.

En segundo lugar, en cuanto al título de imputación, puesto que la responsabilidad penal viene modulada por el grado de intervención en el hecho, responden más gravemente los autores que los cómplices. Pero no ha sido posible realizar un análisis preciso de esta variable por la falta de calidad de los datos disponibles, pues si bien en casi todos los indultos aparece el concepto de autor (por lo que cabría imaginar que sólo se indulta a los autores de las infracciones), las penas aplicadas permiten deducir que no siempre se trata de autores.

Y lo mismo ha sucedido con la variable del grado de ejecución, dado que en numerosos indultos no se hace referencia a este extremo o el delito aparece como

\footnotetext{
${ }^{18}$ De nuevo, al igual que en otras ocasiones ya referidas, el cruce de las dos clases de datos conlleva un inevitable décalage. Sin embargo, no hay razones para suponer que los datos exactos implicarían cambios importantes en la tendencia que se observa de este modo.
} 
consumado pero, al igual que en el caso anterior, se deduce que no siempre se ha perfeccionado la infracción penal.

\subsection{Penas}

Según la Ley de 1870, se pueden indultar o, en su caso, conmutar por otras menos graves, las penas «a que hubiese sido condenado y que todavía no hubiese cumplido el delincuente» (art. 4). De acuerdo con esta disposición legal, la primera variable corresponde a las penas que, con carácter bien principal, bien accesorio, han sido impuestas en la sentencia condenatoria firme y no se han ejecutado. A su vez, teniendo en cuenta que el indulto o la conmutación pueden recaer sobre la totalidad o solo sobre alguna de las penas impuestas, la segunda variable abarca tanto las penas que efectivamente se han indultado, como las penas que han sido conmutadas por otras de menor gravedad.

Dependiendo de la variable utilizada, se puede conocer la naturaleza y gravedad de las penas con las que se ha podido acceder al expediente de concesión del indulto o, en su caso, identificar la clase de las penas afectadas más frecuentemente por los indultos.

Sobre esta base, se han formulado las siguientes hipótesis: en primer lugar, que la mayoría de los indultos afectan a las penas privativas de libertad y, en segundo lugar, que entre las penas privativas de otros derechos, las inhabilitaciones constituyen el grupo más numeroso.

La recogida y la sistematización de la información han tenido determinadas limitaciones que han obstaculizado, en parte, el análisis. En este sentido, cabe mencionar el deficiente modo de registro de la información en los decretos, toda vez que, por ejemplo, se alude a la pena afectada por el indulto con fórmulas vagas (v. gr., indulto de "la pena pendiente de cumplimiento").

En cuanto a los resultados obtenidos del análisis de las variables señaladas, los más significativos son los que se reflejan en el siguiente gráfico: 
Gráfico 8: Distribución según clase de pena

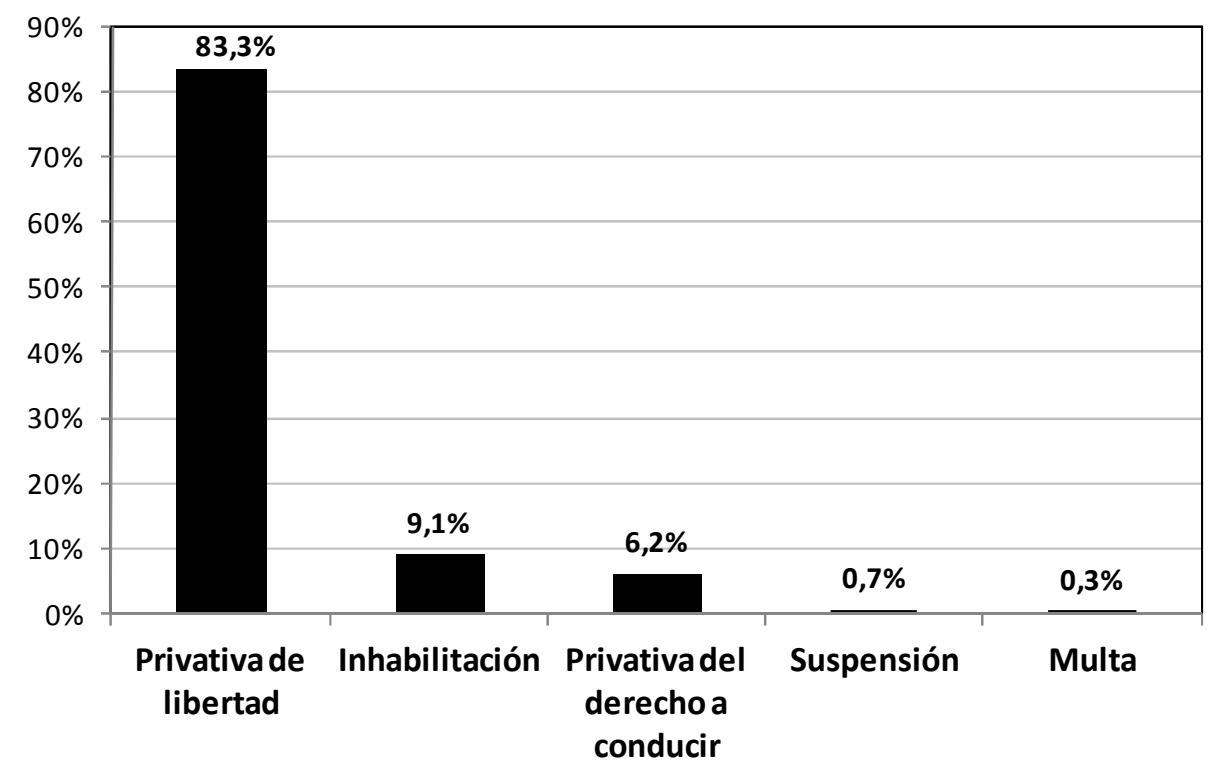

Fuente: elaboración propia.

Como puede apreciarse, en primer lugar, se ha confirmado que las penas privativas de libertad fueron las más frecuentemente indultadas. En concreto, las que afectan a la libertad individual —compuestas, en su inmensa mayoría, por las de prisión- representan el $83,3 \%$ del total de penas indultadas.

En segundo lugar, se ha constatado que entre las penas privativas de otros derechos, las de inhabilitación han sido las más beneficiadas. Ahora bien, en relación con el universo de penas indultadas, representan el 9,1\%.

El gráfico anterior muestra, por último, la menor incidencia del indulto sobre otras penas. No merecen ser consideradas otras que, debido a su escasa representatividad, reflejan valores inferiores a $0,1 \%$ (como las siguientes: privativa del derecho a la tenencia y porte de armas, expulsión del territorio nacional, privativa del derecho de sufragio, arresto sustitutorio por impago de multa, prohibición de aproximación a la víctima o a otras personas, etc.).

\subsection{Características del indulto}

El indulto puede desplegar diversos efectos según el artículo 4 de la Ley: puede dar lugar a la extinción de todas las penas pendientes de cumplimiento (indulto total), puede producir la extinción de sólo algunas de las penas impuestas o de parte de todas 
las impuestas al penado (indulto parcial), o puede, finalmente, consistir en la conmutación de la pena impuesta por otra de menor gravedad (supuesto que la Ley del Indulto también prevé como indulto parcial considerando que no determina la completa extinción de la responsabilidad criminal). En consecuencia, en los casos de indulto parcial, siempre resultará pendiente de cumplirse alguna pena: alguna (o una parte) de las impuestas u otra por la que fuera sustituida la pena impuesta.

El registro de las correspondientes variables ha permitido conocer la clase de indultos que se conceden con mayor frecuencia. La investigación ha confirmado la hipótesis de partida, según la cual la frecuencia de los indultos parciales (y, en particular, de las conmutaciones) superaría a la de los indultos totales. Los datos obtenidos se reflejan en el gráfico siguiente:

\section{Gráfico 9: Distribución según clase de indulto}

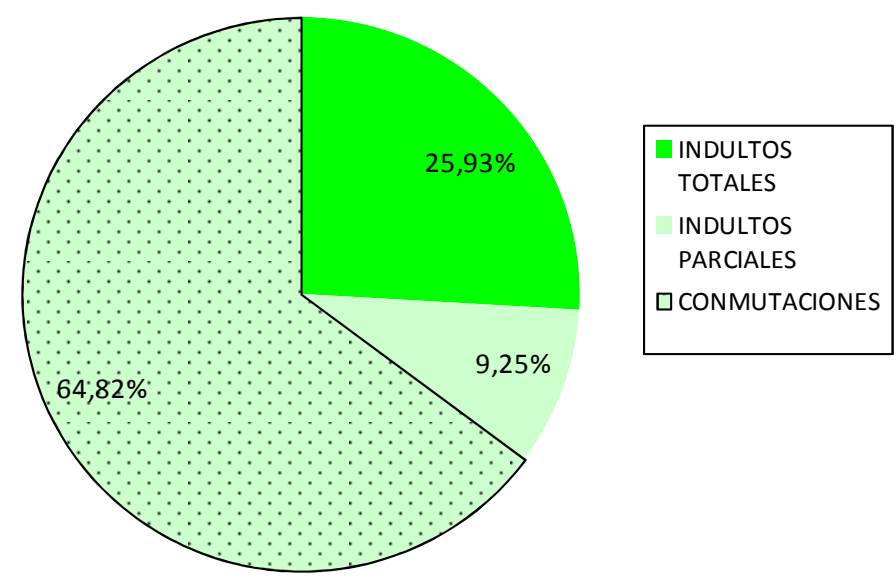

Fuente: elaboración propia.

No obstante, debe hacerse una advertencia con respecto a la calidad de los datos que proporcionan los correspondientes reales decretos, porque en ocasiones la “conmutación" en la que se afirma que consiste el indulto no difiere de un indulto parcial, puesto que comporta únicamente una rebaja de la misma pena a la que fue condenada la persona beneficiada.

Con todo, la conmutación proporciona de hecho una vía para la sustitución extrajudicial de la pena sin tener que someterse a los requisitos establecidos en el artículo 88 del Código penal. 


\subsection{Condiciones impuestas}

El indulto -total o parcial- puede ser condicionado o incondicionado. Esta clasificación se realiza según se haya impuesto, o no, alguna condición, bien para su cumplimiento anterior, bien para su cumplimiento con posterioridad a la concesión del indulto, para que éste surta sus efectos. La regulación de este aspecto en la Ley de 1870 se contiene en los artículos 15 a 17. El artículo 16 permite imponer al penado en la concesión de la gracia "las condiciones que la justicia, la equidad o la utilidad pública aconsejen". En el análisis de esta variable se abordan las condiciones que son impuestas en virtud de este precepto.

En particular, interesa conocer en qué se concretan las condiciones en la práctica; cuáles son, efectivamente, las más frecuentemente impuestas y sus características; qué relación (o correspondencia) se observa con los delitos cometidos o con las penas impuestas; con qué frecuencia se imponen a unos (totales) u otros (parciales) indultos; y cuál es el plazo medio de duración de la condición impuesta.

Para su estudio se ha optado por registrar todas las condiciones, pero como se verá las que con más frecuencia se imponen son las tres siguientes: a) establecimiento de un plazo durante el cual el indultado no puede volver a cometer delitos dolosos; b) obligación de someterse u obligación de no de abandonar un tratamiento deshabituador respecto del consumo de drogas tóxicas, estupefacientes o bebidas alcohólicas hasta la completa rehabilitación; y c) satisfacción de las responsabilidades civiles fijadas en la sentencia en el plazo determinado por el tribunal sentenciador.

Las hipótesis de partida cuya comprobación se pretende con el análisis de esta variable es la siguiente: todos los indultos concedidos, totales o parciales, son condicionados.

De los datos obtenidos en este estudio se ha derivado que los casos en que no se impone una condición no son estadísticamente representativos y se reducen a supuestos particulares y excepcionales ${ }^{19}$. Por ello, es posible confirmar la hipótesis, que ha sido formulada a partir de las declaraciones del Ministro de Justicia en la referida sesión

\footnotetext{
${ }^{19}$ Los supuestos encontrados no llegan a la decena y se refieren a condenas de la Jurisdicción Militar o a supuestos particulares como el indulto de la pena de privación definitiva de obtener el permiso de conducción impuesta en condena de 1963.
} 
parlamentaria de 13 de diciembre de 2000, y según la cual todos los indultos concedidos son condicionados ${ }^{20}$.

De las propias afirmaciones del Ministro se deduce que las condiciones más frecuentes en la concesión del indulto pueden ser generales (mantenimiento de las circunstancias penales y personales acreditadas en el expediente, no comisión de delito doloso en un determinado plazo, obligación de satisfacer las obligaciones civiles u obligación de pagar la multa impuesta) o específicas (no abandonar el tratamiento deshabituador hasta la total rehabilitación).

Pues bien, sentadas ambas premisas - que todo indulto es condicionado y que en todo indulto se imponen ciertas condiciones generales y en algunos casos condiciones específicas-, procede analizar el impacto real de las condiciones habitualmente impuestas. No obstante, entre los datos extraídos no se ha hecho mención expresa a algunas de las condiciones generales que han sido citadas supra, particularmente la relativa al mantenimiento de las circunstancias acreditadas en el expediente y la obligación de pagar la multa impuesta (que sólo podrá ser tenida en consideración, lógicamente, cuando la pena indultada no sea la de multa). Tales condiciones, de ser efectivamente impuestas, no figuran en realidad en los reales decretos.

La condición de mayor frecuencia es la que impone el establecimiento de un plazo durante el cual el indultado no puede volver a cometer delitos dolosos. Los casos en que el decreto no la contempla tienen alguna característica especial como la concesión del indulto por algún privilegio de cofradía ${ }^{21}$ o el sometimiento a la condición de expulsión del territorio nacional sin posibilidad de regreso durante un plazo determinado. Exceptuando estos casos residuales, es posible afirmar que esta condición se impone en todos los casos, no siendo, por tanto, determinantes las demás variables, particularmente el delito cometido, sobre la decisión de imponer o no imponer esta condición.

Respecto de la duración de esta condición se han podido observar los siguientes parámetros: la duración mínima es de 0,1 años y la duración máxima de $163,3^{22}$; la duración media del plazo de la condición es de 3,9 años, si bien la mediana es de 3 años.

\footnotetext{
${ }^{20}$ Manifestaciones realizadas en el seno de la Comisión de Justicia e Interior respecto del acuerdo adoptado por el Consejo de Ministros el 1-12-2000 (DSC, cit., p. 3502).

${ }^{21}$ Así, el privilegio que en el siglo XVIII fue otorgado por Carlos III a la Cofradía Nuestro Padre Jesús el Rico, de Málaga.

${ }^{22}$ En este caso extraordinario se indultaron diversos delitos de asesinato en concurso real.
} 
Por su parte, según los datos extraídos de la muestra, la obligación de someterse o la obligación de no abandonar un tratamiento deshabituador respecto del consumo de drogas tóxicas, estupefacientes o bebidas alcohólicas hasta la completa rehabilitación, tiene una frecuencia de imposición del $12 \%$. Se acuerda de manera cumulativa con la determinación de un plazo de no comisión de delitos dolosos.

La tercera condición, referida a la satisfacción de las responsabilidades civiles fijadas en la sentencia en el plazo determinado por el tribunal sentenciador, es también la tercera respecto de la frecuencia de imposición. Los datos arrojan un índice de imposición de 6\%. La carencia de datos sobre el plazo medio de imposición en esta condición es debido a que no aparece reflejado en el decreto de concesión del indulto puesto que su fijación es dejada en manos del tribunal sentenciador. Al igual que en el caso de la anterior condición, se impone conjuntamente con la prohibición de comisión de delitos dolosos.

Finalmente, en los datos extraídos se observa la presencia de otras cuatro clases de condiciones que han sido acordadas en la concesión del indulto. No obstante, carecen de significación estadística, dada su incidencia apenas apreciable, ya que se reduce a un solo caso para cada condición: expulsión del territorio nacional sin posibilidad de regreso durante un plazo de 10 años, asunción del pago de una indemnización solidaria de 60101 euros, continuación con el sometimiento a revisiones médicas periódicas, y obligación de someterse a tratamiento psiquiátrico.

No se ha recogido ninguna otra condición diferente de las expuestas, como, por ejemplo, la imposición de prohibición de aproximación a la víctima que sí ha sido utilizada en otras ocasiones ${ }^{23}$.

\section{DISCUSIÓN}

La falta de datos estadísticos de acceso público en España sobre los indultos dificulta notablemente el conocimiento de la práctica de su concesión, pues solamente puede reconstruirse a partir de la información que aportan los reales decretos mediante los que son otorgados. Por esta razón, el objetivo de este trabajo ha sido presentar las primeras conclusiones obtenidas a partir de los datos correspondientes al periodo 2000-

\footnotetext{
${ }^{23}$ Esta condición de cumplimiento posterior a la concesión de indulto es, a juicio de Sánchez-Vera, una conmutación de la pena por una menos grave, que daría lugar a lo que el autor caracteriza como "indulto impropio" (2008, p. 21).
} 
2008 , en el que se han sucedido dos legislaturas bajo gobiernos de signo político diferente.

El estudio ha permitido conocer algunos datos absolutos como los siguientes: que el Gobierno del Partido Popular indultó a más personas que el Gobierno del Partido Socialista; que se indultó a más hombres que mujeres (aunque las mujeres fueron - en términos relativos - indultadas con mayor frecuencia); que la mayoría de las condenas indultadas fueron las que alcanzaron firmeza en las audiencias provinciales; que la provincia de la que procedían más condenas beneficiadas por los indultos fue Madrid (seguida de Barcelona); que se indultó — prácticamente - toda clase de delitos (y también faltas); que los más indultados fueron los llamados "delitos contra la salud pública" (aunque —en términos relativos-resultaron ser los delitos contra la Administración Pública); que dominaron los indultos parciales sobre los totales; que todos fueron sujetos a alguna condición y que la pena más frecuentemente afectada por el indulto fue la pena de prisión.

Sin embargo, como se ha puesto reiteradamente de manifiesto en este trabajo, el modo en que se plasman los datos en los decretos es poco regular y está insuficientemente estructurado para los fines de la investigación. Estas deficiencias impiden contar con información sobre algunos aspectos que sería muy valioso conocer, como el título de imputación de la persona beneficiada después por el indulto, el grado de ejecución del delito indultado o las penas concretamente extinguidas tanto en su clase como en su duración. Ello podría ser evitado en el momento de la redacción de los correspondientes reales decretos de otorgamiento de los indultos recogiendo, además de los datos ya contenidos sobre el órgano sentenciador, las variables temporales y las condiciones impuestas, referencias como las siguientes: el concreto delito cometido, el grado de ejecución alcanzado (actos preparatorios, consumación o tentativa), el título de imputación (autor o cómplice), la pena efectivamente indultada, el origen de la solicitud del indulto y el motivo que lo justificó.

Desde el punto de vista de la función que desempeña el indulto, el estudio ha permitido constatar que en su uso no están en absoluto ausentes las razones de política criminal, sino que inciden en su régimen de un modo claro ${ }^{24}$ (aunque en menor medida,

\footnotetext{
${ }^{24}$ Conforme a la concepción de la "política de indultos" como "una manifestación de la política criminal del gobierno". Así, expresamente, el ex Ministro de Justicia, Sr. López Aguilar, ante la Comisión de Justicia del Congreso en la sesión de 25-5-2004 (DSC, Comisiones, Justicia, VIII Legislatura, núm. 33, 2004. Sesión n ${ }^{o} 2$ de la Comisión de Justicia, p. 39).
} 
en todo caso, del que presumen los Gobiernos, tanto en lo que se refiere a las clases de delitos indultados como en cuanto a las penas correspondientes).

En fin, la información obtenida resulta de gran interés por obvias razones de transparencia democrática, además de por motivos técnicos, dada su utilidad para detectar problemas motivados en la práctica por las leyes penales. Por ejemplo, la última reforma del Código penal, debida a la L.O. 5/2010 por la que se modifica la L.O. 10/1995, del Código Penal, ha afectado, precisamente, a los delitos de tráfico de drogas, cuya excesiva penalidad puede ser la razón que explique muchos de los indultos concedidos por los "delitos contra la salud pública", que han alcanzado en nuestra investigación el valor absoluto más alto. También la reforma de los delitos contra la propiedad industrial e intelectual en lo que afecta a los hechos de los denominados "manteros", debida a la misma Ley, ha podido estar influida por la presión recibida desde medios jurídicos a través de diversas iniciativas, entre las que ha sido singularmente destacada la promoción de las peticiones de indulto ${ }^{25}$.

Por último, la falta de motivación de los indultos (concedidos y denegados) y la imposibilidad de revisión en casación de las decisiones adoptadas sobre el ejercicio del derecho de gracia, que confirma insistentemente el Tribunal Supremo ${ }^{26}$ otorga a esta institución unos rasgos de tal excepcionalidad en el contexto del Estado de Derecho que aconsejan una atenta observación de su empleo en la práctica. A este fin ha pretendido servir el presente trabajo.

${ }^{25}$ Vid. http://www.inmigrapenal.com/ > Manteros > Presentación (consultada el 11-10-2011).

${ }^{26}$ Así, recientemente, con más referencias, la STS (Sala de lo Contencioso-Administrativo) de 12-5-2011. 


\section{REFERENCIAS BIBLIOGRÁFICAS}

Aguado Renedo, C. (2001). Problemas constitucionales en el ejercicio de la potestad de gracia. Madrid: Civitas.

Borja Jiménez, E. (2011): Curso de Política criminal. Valencia: Tirant lo Blanch.

Cid, J. \& Tébar, B. (2010): Spain. En N. Padfield, D. van Zyl Smit \& F. Dünkel (Eds.), Release from prison: European policy and practice, Cullompton: Willan Publishing.

García Mahamut, R. (2004): El indulto: un análisis jurídico-constitucional. Madrid: Marcial Pons.

López Aguilar, J. F. (1996): Una reflexión a propósito del control parlamentario del derecho de gracia. Revista de las Cortes Generales, 37, 329-342.

Rodríguez-Zapata y Pérez, R. (1987): Sanción, promulgación y publicación de las leyes. Madrid: Tecnos.

Sánchez-Vera Gómez-Trelles, J. (2008): Una lectura de la Ley de Indulto. InDret: Revista para el análisis del Derecho, 2/08, 1-32. Disponible en: http://www.indret.com/es/index.php 